\title{
Psychrobacter immobilis
}

National Cancer Institute

\section{Source}

National Cancer Institute. Psychrobacter immobilis. NCI Thesaurus. Code C86708.

A species of aerobic, Gram negative, rod and cocci shaped bacteria assigned to the phylum Proteobacteria. This species is catalase and oxidase positive, penicillin susceptible, urease positive and salt tolerant. P. immobilis exhibits low virulence and is pathogenic only in rare cases. 